\title{
Quizrevision: A Mobile Application using the Google MIT App Inventor Language Compared with LMS
}

\author{
Mohamed A. Amasha \\ Department of Computer Teacher Preparation-Damietta, \\ Egypt
}

\begin{abstract}
At Qassim University, the Blackboard (https//:Ims.qu.edu.sa) Learning Management System (LMS) is used. An exploratory study was conducted on 105 randomly selected students attending Qassim University. Of these, 91 students $(\mathbf{8 7} \%)$ affirmed that they did not use the LMS as a study aide. This paper describes the means by which the MIT App Inventor language could be used to develop a mobile application (app) for the Android operating system. The app, Quizrevision, enables students to review course knowledge and concepts. An online survey was used to investigate students' perceptions and gather their feedback regarding the use of Quizrevision as a study aide, as compared to the LMS. An achievement test was used to examine the improvement of students' scores. Data was collected from 114 students taking the Phonetics course (Arab 342) in the Arabic Language Department (ALD) of Qassim University; 63 of them $(55.27 \%)$ were male, and 51 (44.73\%) were female. Descriptive statistics, chi-square, and t-test were used to analyze the data. The results indicated that the Quizrevision app supported the students' achievement. There was a positive attitude towards using the Quizrevision app, as well as higher engagement in using the app as compared with using the LMS. In addition, findings confirm that students prefer using m-learning apps rather than using LMSs for reviewing course concepts and knowledge. Furthermore, student scores improved after using the app.
\end{abstract}

Keywords-Quizrevision; mobile application; LMS; e-learning; e-course; MIT APP Inventor; Android devices

\section{INTRODUCTION}

Nowadays, the development and progress of information technology (IT) has resulted in many technological innovations that can be employed in the educational process [17]. Accordingly, many countries have already adapted their educational system to employ these technologies. Typically, universities, colleges and other educational institutions start presenting their training program via the internet, in a model known as e-learning. E-learning is a modern style of education that helps to simplify the educational process [12]. It enables both the teacher and the students to communicate within interactive educational environments. In this respect, elearning is a significant aide in improving teaching and learning processes [11]. Boticki, Baska, Seow and Looi (2015) studied the design of a mobile learning platform called samEx as a virtual bages in elementary school. They discussed the design and analyzed the data regarding student use. Qun wu (2015) carried out a study to design a smartphone app to teach English Level 2 vocabulary, and investigated its effectiveness as a tool in helping college students classified as speaking

\author{
Shaimaa Al-Omary \\ Department of Curricula and Teaching Methods (Arabic \\ Language) \\ Cairo, Egypt
}

English as a foreign language (EFL) to learn English vocabulary. Guerrero, Ochoa and Collazos (2010) conducted a study in improving grammar skills in elementary school students. They presented the design of a collaborative learning activity and designed a software application to support teaching grammar through mobile devices. Yang, $\mathrm{Li}$ and $\mathrm{Lu}$ (2015) investigated the interactions of internet and presentation mode on students' concentration and achievement in learning conceptual knowledge through mobile phones in the classroom setting. Previous studies in the same field did not address any application in the Arabic language or their influence on students of the Arabic Language Department. Furthermore, they did not address the advantages of designing mobile applications using the MIT App Inventor language. Finally, there is no research that compares the use of mobile applications and learning management systems, either in general or in the Arabic department specifically.

In this paper, we examined what motivated students in the Arabic Language Department (ALD) to interact using modern technology. In addition, we tried to leverage the widespread use of smart devices among students. Quizrevision was designed as a trial with a sample of ALD students (114) over a period of one academic year, to support and complement the learning process. We discuss the design of Quizrevision and analyze student feedback regarding use of the application. We hoped to see an improvement in students' scores after they used the app. We hope this study will pave the way for other researchers to use this technology to design other tools for reviewing Arabic language courses.

\section{THEORETICAL BACKGROUND}

The development of e-learning is highly associated with the development of communication and information technology, which are becoming widely used in education [4]. This rapid development spurs educational researchers to search for new methods, which suit the characteristics of this development and help students to learn; e-learning cannot be overlooked, as it is the fastest-growing methodology [35]. Mobile learning, or m-learning, is considered a new phase in e-learning. Both the great development in communication and education technology, as well as the spread of e-knowledge among students at schools and universities has led to the emergence of new learning systems, such as m-learning. Mlearning enables easy access to content, and it provides many opportunities for learning outside the classroom [4]. The widespread use of e-learning has led to the appearance of 
learning management systems, which manage, monitor, and design learning. LMS systems also manage e-courses and follow up on student achievement [9]. Students are encouraged to use the LMS in studying the e-content [33]. In spite of the appearance of the social media and Web 2.0 tools (such as Facebook, Twitter, Linkdin, Wiki, and RSS) [18], [19] many universities prefer using LMS [27]. The many possibilities of the system as an integrated e-environment help to integrate social networks with it. As such, communication via both the system and the social network can be employed through m-learning, which is considered to be a model for $\mathrm{m}$ learning [29].

\section{A. App Inventor (AI)}

App Inventor (AI) is an open-source, web-based system that enables developing a mobile application for Android operating system (OS) devices. It is an online development environment (ODE). Google Inc. and the Massachusetts Institute of Technology (MIT) developed AI in 2012. AI is a visual drag-and-drop programming tool [25]. Furthermore, it relies on a web-based graphical user interface (GUI) builder [7]. With this programming tool, programmers can produce and develop educational applications for mobile phones. AI is widely used because it utilizes an integrated programming editor that contains several tools to help programmers in producing and designing their apps [32]. It relies on a type of programming known as a blocks-based programming language [6]. AI helps both teacher and learner to create their apps on Android devices as fun, quick prototypes, with educational games and quizzes for classmates. AI can be used online through browsers like Chrome or Firefox.

\section{B. Mobile learning (m-learning)}

Nowadays, e-learning and m-learning have become key concepts in education as part of the technological revolution [8]. M-learning is considered the most well-known emerging technology, of those that support e-learning and online learning [13]. M-leaning enables learners to learn anywhere, at any time, through using cell phones, PDAs and smartphones to facilitate the exchange of information between teachers and students. The next-generation LMS should be mobile-friendly, personalized, customizable, adaptive, intuitive, integrated, and designed to enhance student learning. Furthermore, there are plenty of universities and institutions that use mobile phones in learning, since they allow students to surf the internet during lectures. Additionally, others use mobile phones to capture what is on the board [21].

\section{Learning management systems (LMS)}

Learning management systems (LMS) have become the most prevalent educational environment, since they organize and manage e-learning processes [34]. Recently, many universities have begun using an LMS in their educational systems. There are currently two brands of LMS. The first is open-source software, called Moodle. The second is commercial software, called Blackboard [15]. Blackboard includes several tools, such as learning and teaching activities, assignments, e-content, course organization, discussion board and virtual classroom [9] [26]. In addition, an LMS can be integrated with traditional educational methods to create blended learning. It can also support distance education [12].
It is generally agreed that an LMS helps to shift from traditional learning to e-learning by adopting content design standards such as IEEE, IMS, and SCORM. It requires an internet connection and can perform the following tasks: administration, publishing and writing reports. Moreover, an LMS consists of the following main parts: admission, ecourse, synchronous learning, non-synchronous learning, etest, discussion forums and electronic supervision. In fact, the first generation of e-learning is called "classic e-learning" and consists of adding a computer and the internet to the LMS. The second generation of e-learning is called "advanced elearning"; it consists of mobile and wireless access in addition to VR/AR.

\section{HYPOTHESES}

This paper aims to use the MIT App Inventor language to develop a mobile app that enables students to review course knowledge and concepts, following participation in the course entitled the Phonetics course (Arab 342). The study aims to gather student feedback about using Quizrevision as a reviewing tool compared to an LMS. The study poses the following hypotheses:

H1: Students have positive attitudes towards using Quizrevision in reviewing the course entitled the Phonetics course (Arab 342).

H2: Students prefer using an m-learning app over an LMS for reviewing the course.

H3: There are statistically significant differences (at $\mathrm{p}<$ 0.05 ) between males and females regarding the use of $\mathrm{m}$ learning as a reviewing tool for the course.

H4: The degree of students achievement have been improved and there is a statistically significant difference (at $\mathrm{p}$ $<0.05)$ between the mean scores of the pre- and post-tests following use of the Quizrevision app as a reviewing tool.

\section{METHODOLOGY}

\section{A. Instructional Material Design}

The project was carried out using student in an ALD course, Phonetics course (Arab 342). We conducted interviews with a cohort of professors (15) from ALD at Qassim University. Thirteen (86.8\%) agreed on the difficulty of this course and stressed the importance of a good review before the exam. Professors of ALD compiled the content of the course and then arranged it according to the relative importance of each part, based on the professors' opinion. The content appeared as a booklet before its final form. It was divided into five parts: 1) important definitions; 2) phonetics; 3) the place of articulation; 4) illustrated explanation; and 5) test yourself. These sections would enable the students to fully review the content of the course. The app included a presentation of the behavioral goals for each part of the app and what the student should have learned by the end of the course. The app was designed to allow the students to navigate easily through links to access information. Furthermore, the app provided students with feedback through the Test Yourself icon. Before the programming process, the content was offered to a group of professors (the jury) in the Arabic 
language, so they could express their opinions about its validity and how it was related to the preset targets. Hence, the validity of the content for the app was achieved.

\section{B. Project Approach}

The App Inventor language was selected as Quizrevision's design language. The following procedures were required: First, a Gmail account was created. Second, Java 1.6 was downloaded from http://www.java.com before starting. To design and develop the app, we used the block editor and inventory palette components (user interface, layout, media, and sensors). AI included the block editor, which was implemented as a Java Web application to start designing the application. It required installing Java on the desktop. AI exported a file package as an APK file, which could be published and distributed on Android devices. In addition, AI provided a QR code for the APK file.

To design the Quizrevision app and write the code that would help to solve the research problem, the problem inputs, mathematical and logical processes were identified and the problem outputs were specified. Hence, a flowchart was drawn to illustrate the steps required to implement the program. Fig. 1 shows the research algorithm. The flowchart was converted into a group of commands using MIT's App Inventor language.

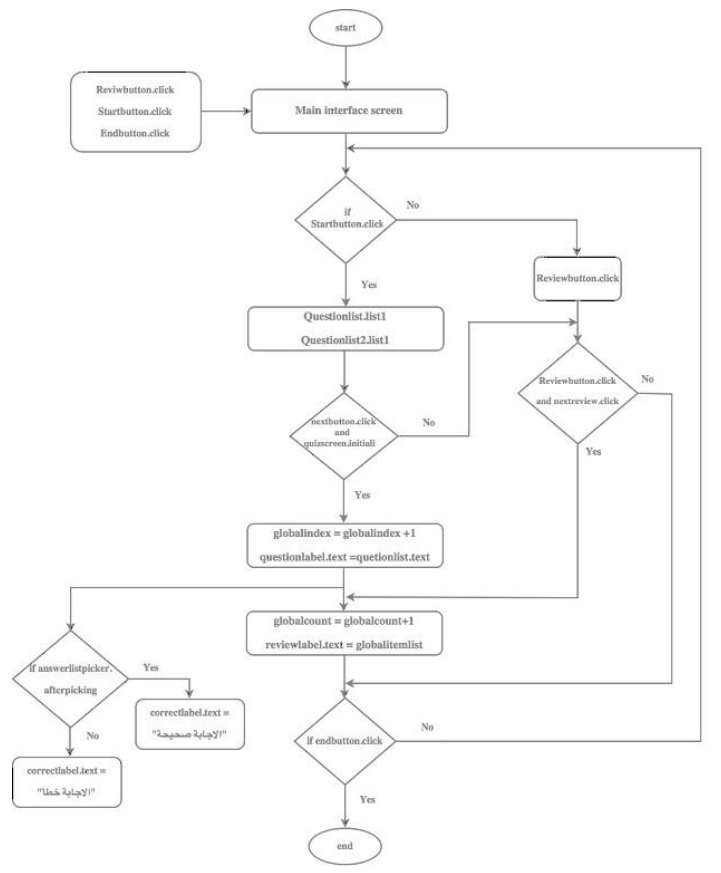

Fig. 1. The research flowchart

After the app was designed, it was published and run on the desktop, and then on the Android devices after launching the MIT AI2 Companion on the device and then scanning the barcode or typing in the code to connect for live testing of the app. The results of the app after publishing were compared with Fig. 2. In addition, Fig. 3 shows the MIT App Inventor block code.

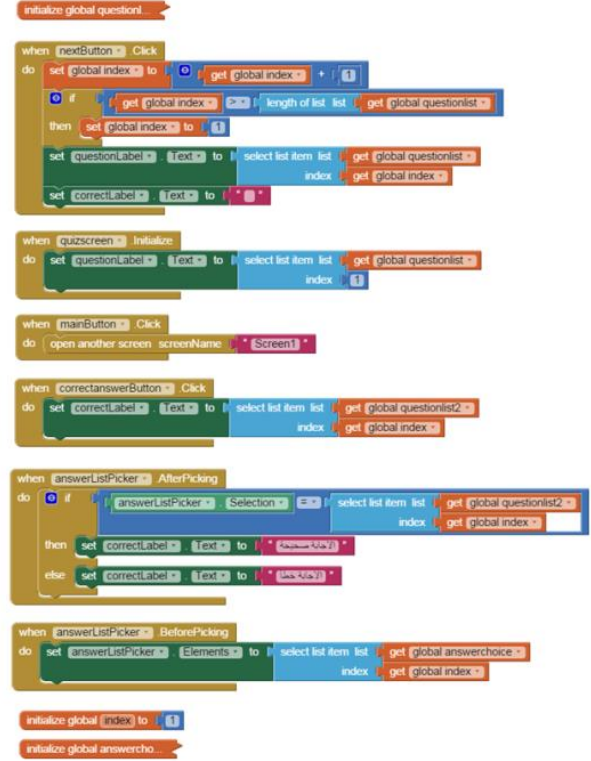

Fig. 2. MIT APP Inventor code

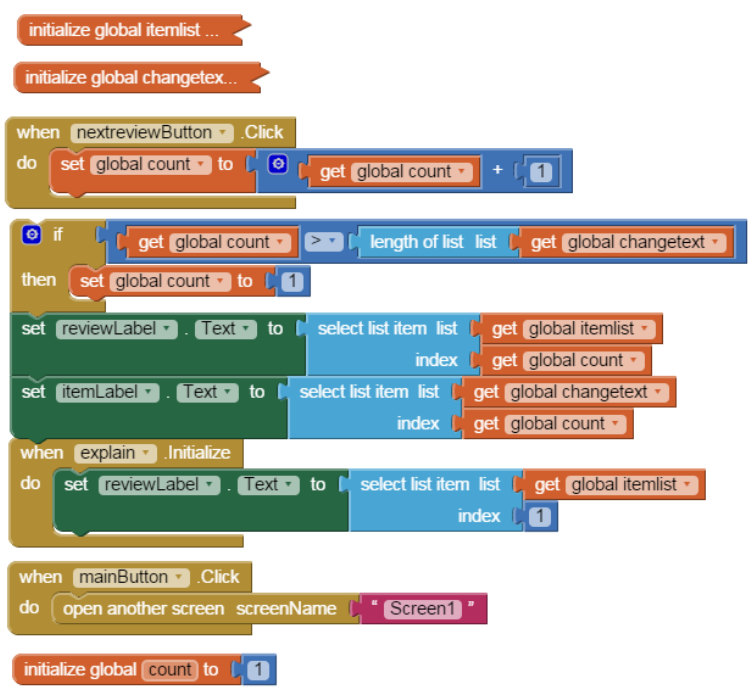

Fig. 3. MIT App Inventor code

As the code was written, the app was reviewed and prepared for publishing. Therefore, to publish the app, a Google Play developer account was created by the developer console. Then the APK file was uploaded to Google Play through "upload your first APK to production". The app properties were organized by store listing and were free. Accordingly, the app was published in Google Play under the name "quiz revision ARAB 342". The main interface menu and the app's icon in Google Play are shown in Fig. 4 and 5. After the course was completed in the 11th week, four weeks were devoted to reviewing the course. Two lectures per week were reviewed. The students were asked to bring their tablets and to download the application from Google Play. During the last week, they used the app to take a comprehensive test. 


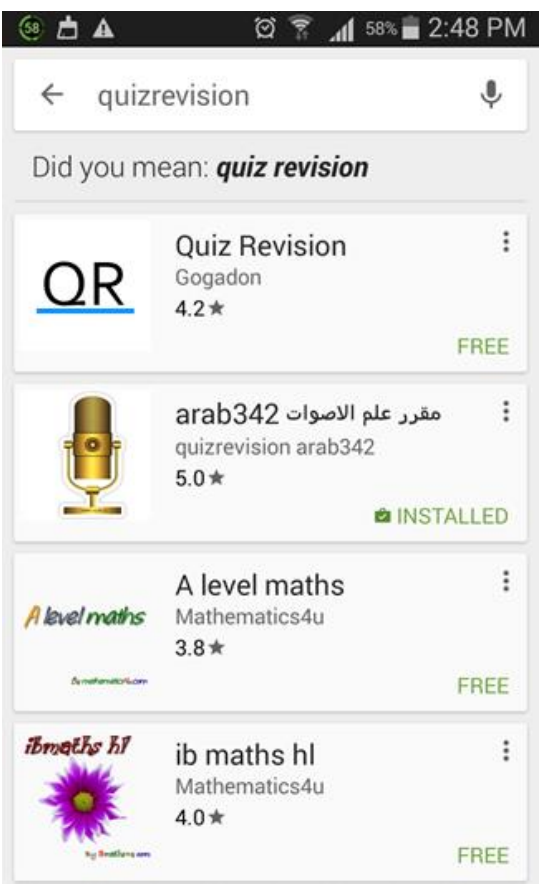

Fig. 4. App icon in Google Play

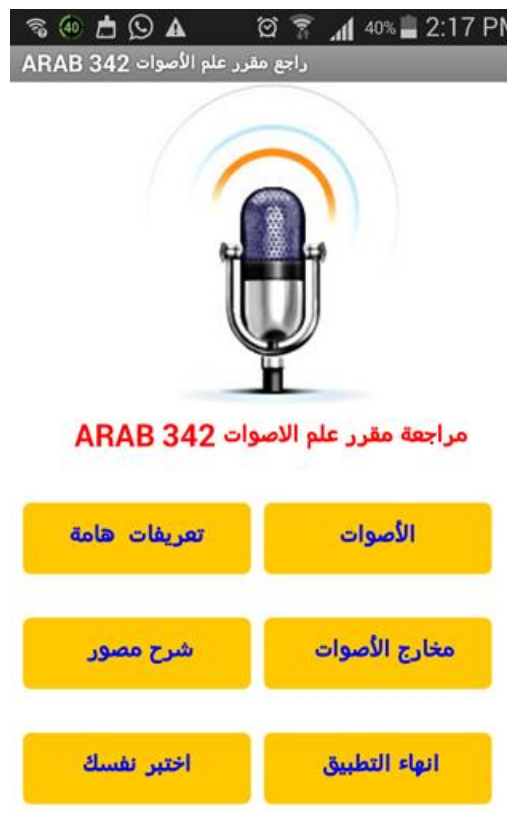

Fig. 5. Main menu in the user interface

\section{Participants}

Data was collected from 114 students at Qassim University; they contributed to the survey voluntarily. They comprised 114 college students, as shown in Fig. 6. Of these, $63(55.27 \%)$ were male and $51(44.73 \%)$ were female. All participants took the phonetics (Arab 342) course, at ALD at Qassim University. After they completed the course, Quizrevision was presented to them to review the course concepts and information. A link to the online questionnaire
(http://goo.gl/forms/gKOQQ9Pe6y) was sent to them through e-mail and they were asked to complete the questionnaire.

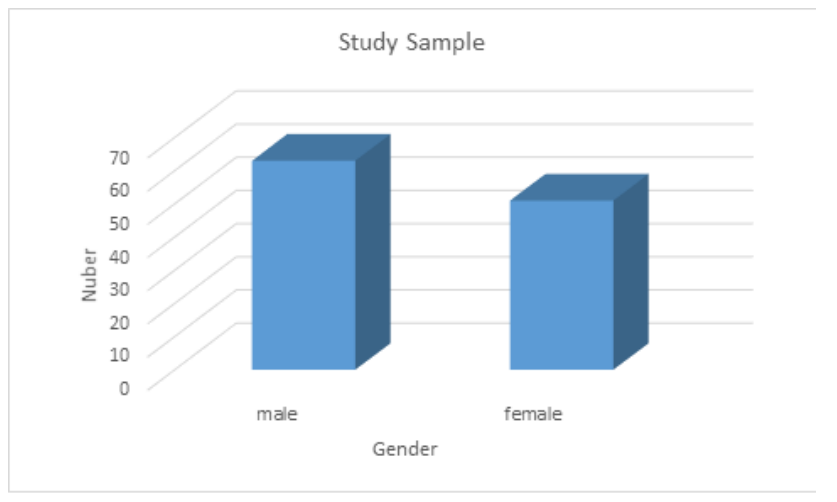

Fig. 6. Study participants

\section{Measurement Instrument}

A questionnaire was designed for the purposes of this study and distributed to some selected professors to express their opinions about the questionnaire and to edit its contents. The questionnaire consisted of 23 items with six constructs as follows:

1) Usage and accessibility (UA),

2) Clarity of content (CC),

3) Effectiveness of learning (EL),

4) Compared with LMS (CL),

5) Attitude toward using the app (AU), and

6) Impression of app (IP).

The measurement items were based on a five-point type Likert scale, ranging from strongly disagree (1) to strongly agree (5). The internal consistency reliability was 0.87 and Cranach's $\alpha(\geq 0.98)$, which was used to evaluate the reliability of the instrument. Therefore, the questionnaire had acceptable reliability for the application.

\section{RESULTS}

\section{A. Analysis of Measurement}

Both discrimination and internal consistency validity were collected for measurement after Cranach's $\alpha(\geq 0.98)$ was computed. Discrimination validity ranged from 0.735 to 0.935 . Discrimination was confirmed by examining the correlation coefficient among constructs of the measurement to exclude any weak or negative items; no item was excluded. The correlation matrix between constructs is shown in Table 1.

TABLE I. CORRELATION MATRIX BETWEEN CONSTRUCTS

\begin{tabular}{|c|c|c|c|c|c|c|}
\hline Constructs & UA & $\mathrm{CC}$ & EL & $\mathrm{CL}$ & $\mathrm{AU}$ & IP \\
\hline UA & - & & & & & \\
\hline $\mathrm{CC}$ & $.876^{* *}$ & - & & & & \\
\hline EL & $.804^{* *}$ & $.862^{* *}$ & - & & & \\
\hline CL & $.780^{* *}$ & $.796^{* *}$ & $.914^{* *}$ & - & & \\
\hline $\mathrm{AU}$ & $.735^{* *}$ & $.768^{* * *}$ & $.869^{* *}$ & $.868^{* * *}$ & - & \\
\hline IP & $.801^{* *}$ & $.829^{* *}$ & $.881^{* *}$ & $.916^{* *}$ & $.882^{* *}$ & 1.00 \\
\hline
\end{tabular}


Usage and accessibility (UA), Clarity of content (CC), Effectiveness of learning (EL), Compared with LMS (CL), Attitude toward using the app (AU), Impression of app (IP)

The internal consistency validity was collected to ensure there were associations between constructs and the questions of the instrument as a whole. As shown in Table 2, the value of the internal consistency validity ranged from 0.843 to 0.935 . The value refers to an acceptable value of internal consistency validity which is statistically significant (at $\mathrm{p}$ $<0.05$ ) in general. Acceptable value reliability is 0.70 . Therefore, the measurement items had both validity and reliability and there was a strong correlation between the correlation coefficient and items of each construct.

TABLE II. DISCRIMINATION VALIDITY OF CONSTRUCTS

\begin{tabular}{ccc}
\hline Constructs & AV & Cronbach's Alpha \\
& & \\
\hline UA & 15.78 & $.843^{* *}$ \\
CC & 11.30 & $.883^{* *}$ \\
EL & 18.92 & $.935^{* *}$ \\
CL & 14.71 & $.922^{* *}$ \\
AU & 14.79 & $.883^{* *}$ \\
IP & 11.29 & $.929^{* *}$ \\
\hline & 2-tailed p values; & p $<0.05,{ }^{* *} \mathrm{p}<0.01$.
\end{tabular}

\section{B. Hypothesis Testing}

In order to examine the research hypotheses, the constructs of the instrument were analyzed and descriptive statistics and chi-square $\left(\mathrm{x}^{2}\right)$ were collected, as shown in Table 3. Test results showed that the mean (SD) value ranged from 3.60 (1.544) to $4.16(1.229)$, the $x^{2}$ value ranged from 26.70 to 122.35 , and all the values were statistically significant (at $p$ $<0.05$ ). Regarding the first hypothesis of the research, students had a positive attitude toward using Quizrevision in reviewing the Phonetics course (Arab 342) course. The researchers used the constructs Attitude toward using the app (AU) and Impression of app (IP) to test the first hypothesis. As shown in Table 3, all items of AU and IP were significant, as follows: $\mathrm{AU} \rightarrow \mathrm{x}^{2}(\mathrm{~b} 1=34.86, \mathrm{~b} 2=36.26, \mathrm{~b} 3=26.70, \mathrm{~b} 4=32.14, \mathrm{p}<.05)$. The results indicate that students used the app while reviewing the course material; this gave them self-confidence, thus they had a positive attitude toward using the app $\mathrm{IP} \rightarrow \mathrm{x}^{2}$ (b1= 51.61, b2 $=43.45, \mathrm{~b} 3=32.57, \mathrm{p}<.05$ ). According to the results shown in Table 3, the students indicated they had a positive impression of the app. For the second research hypothesis, students preferred using the m-learning app rather than the LMS to review the course. We used the constructs Effectiveness of learning (EL) compared with LMS (CL) to examine the second hypothesis. The results, displayed in Table 3, show that all items the constructs EL and CL were significant, as follows: (EL) $\rightarrow \mathrm{x}^{2} \quad(\mathrm{~b} 1=61.11, \mathrm{~b} 2=44.86$, $\mathrm{b} 3=61.08, \mathrm{~b} 4=72.88, \mathrm{~b} 5=64.38, \mathrm{p}<.05)$. The students ensured that using the app as a reviewing tool provided them with quick feedback to support their knowledge and grasp of course concepts. According to the results in Table 3, (CL) $\rightarrow \mathrm{x}^{2}$ (b1=51.96, b2=97.84, b3=50.56, b4=56.96, p <.05). The students reported that they preferred using the app over the LMS, since it is more interesting and attractive.
TABLE III. MEANS, STANDARD DEVIATIONS (SD), ChI-SQUARE AND RELIABILITY FOR CONSTRUCTS OF THE INSTRUMENT

Constructs
Usage and
accessibility
Clarity of
content

Effectiveness of learning

Con

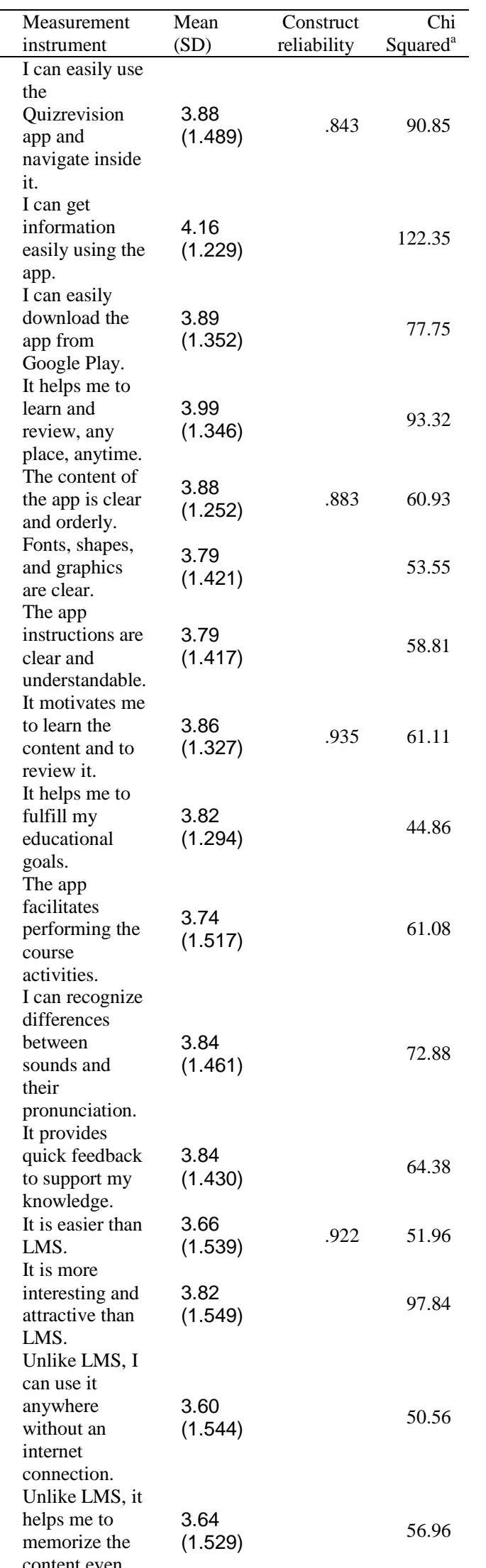




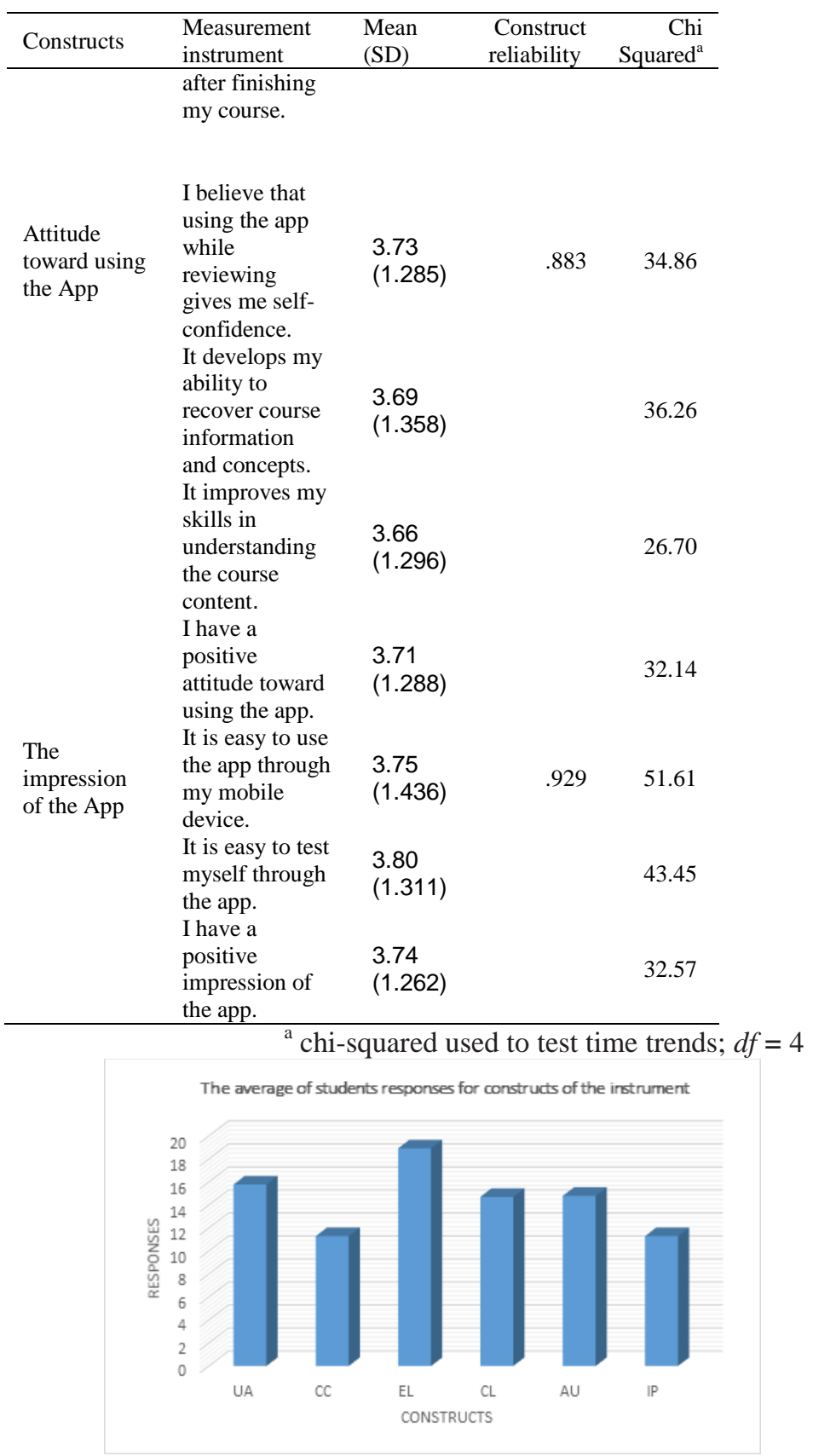

Fig. 7. Student responses for constructs of the instrument

TABLE IV. INDEPENDENT SAMPLES TEST

\begin{tabular}{|c|c|c|c|c|c|c|}
\hline Constructs & Gender & $\begin{array}{l}\text { Mean } \\
\text { (SD) }\end{array}$ & MD & $t$-value & $\mathrm{df}$ & $\begin{array}{l}\text { Sig.(2- } \\
\text { tailed) }\end{array}$ \\
\hline \multirow[t]{2}{*}{ (UA) } & Male & $\begin{array}{l}16.22 \\
(4.77)\end{array}$ & 0.98 & 1.041 & 112 & $0.300^{*}$ \\
\hline & Female & $\begin{array}{l}15.24 \\
(5.34)\end{array}$ & & & & \\
\hline \multirow[t]{2}{*}{ (CC) } & Male & $\begin{array}{l}11.54 \\
(3.87)\end{array}$ & 0.54 & 0.717 & 112 & $0.475^{*}$ \\
\hline & Female & $\begin{array}{l}11.00 \\
(4.14)\end{array}$ & & & & \\
\hline \multirow[t]{2}{*}{ (EL) } & Male & $\begin{array}{l}19.10 \\
(6.52)\end{array}$ & 0.39 & 0.321 & 112 & $0.749^{*}$ \\
\hline & Female & $\begin{array}{l}18.71 \\
(6.37)\end{array}$ & & & & \\
\hline (CL) & Male & 14.98 & 0.61 & 0.571 & 112 & $0.569^{*}$ \\
\hline
\end{tabular}

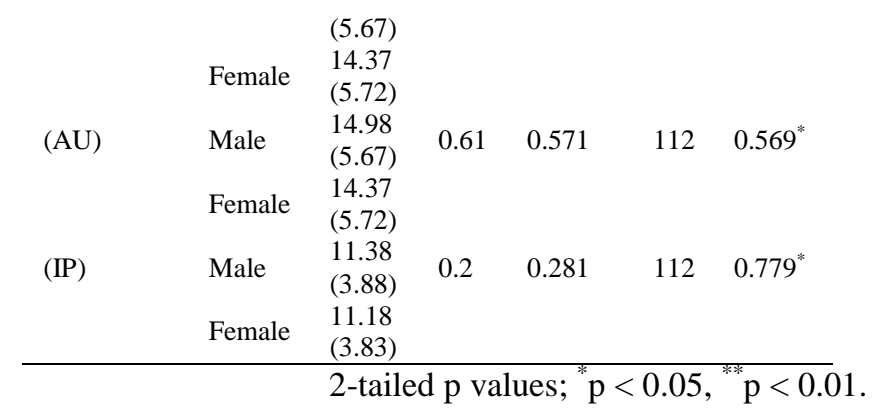

In order to examine the third hypothesis of the research, the t-test value was calculated, which shows the difference between the participants (at $\mathrm{p}<0.05$ ) in the groups (male, female) regarding constructs of the instrument. Table 4 shows that participants in the groups have a score of: male (16.22), female (15.24); the mean difference (MD) is 0.98 while sig. $=$ $0.300>0.05$, $\mathrm{t}$-value is 1.041 , and $p=0.01$. Therefore, there is no statistical significance (at $p<0.05$ ) between the test groups' opinions of the construct of UA. This result means that students have a positive impression of the construct of Usage and accessibility (UA), and the opinions of the two groups are the same. (Note: mean difference $=\mathrm{MD}$, standard deviation $=\mathrm{SD}$, freedom of degree $=\mathrm{DF})$. As shown in Table 4, there is no statistical significance (at $\mathrm{p}<0.05$ ) between the test groups' opinions of the construct of CC, while sig. $=.475>$ 0.05 and $t$-value is $.717, p=0.01$; accordingly, the students agree on the construct of Clarify the content (CC). The students agree on the construct EL, as shown through the tvalue of $.321, p=.749$. We can ensure that there is no statistical significance (at $\mathrm{p}<0.05$ ) between the test groups' opinions about the construct of EL. Table 4 shows that the students preferred the Quizrevision app to the LMS, with a tvalue of $0.571, p=0.01$. Therefore, there is no statistical significance (at $\mathrm{p}<0.05$ ) between the groups' opinions about the construct of CL. The participants in the test groups have the same opinion of using the app. The results in Table 4 illustrate that the $t$-value is $0.571, p=0.01$. They agree on using Quizrevision as a reviewing tool because it enables them to develop their skills in recognizing course information and concepts. They also agree on the ease of learning the course through the app. There is no statistical significance (at $p<$ 0.05 ) between the groups' opinions about the construct of IP, where t-value is .281, $p=0.001$. The Student responses for constructs of the instrument are shown in Fig. 7.

TABLE V. T-TeSt AND DESCRIPTIVE RESUlts

\begin{tabular}{llllll}
\hline Gender & $\begin{array}{l}\text { Pre-group } \\
\text { Mean (SD) }\end{array}$ & $\begin{array}{l}\text { Post-group } \\
\text { Mean (SD) }\end{array}$ & t-value & df & $\begin{array}{l}\text { Sig.(2- } \\
\text { tailed) }\end{array}$ \\
\hline Male & $24.22(7.56)$ & $44.62(3.56)$ & 18.63 & 61 & $0.000^{*}$ \\
Female & $31.71(5.93)$ & $47.25(1.89)$ & 16.55 & 49 & $0.000^{*}$ \\
\hline
\end{tabular}

To examine the fourth hypothesis of the research, which provides for "The degree of students achievement have been improved and there is a statistically significant difference (at $\mathrm{p}$ $<0.05)$ between the mean scores of the pre- and post-tests after using the Quizrevision app as a reviewing tool." The ttest value was used to validate the hypothesis; results are shown in Table 5. There is a statistically significant difference between the mean scores of the study group score after using Quizrevision in reviewing the course. This indicates that the 
fourth hypothesis of the study is confirmed, in terms of the effectiveness of the proposed program in knowledge acquisition of the proposed unit for the students. This result is due to the degree to which the students improved after using the app as a reviewing tool.

\section{CONCLUSIONS}

The purpose of this study was to provide students of the Phonetics course (Arab 342) with an alternative tool for reviewing that would enable them to review course knowledge and concepts. We were interested in motivating students to interact using modern technology. Moreover, the scores of students were improved after using the app. We used MIT's App Inventor language to design the application. The app, Quizrevision, was designed to provide students in the Phonetics course (Arab 342), with quick feedback to support their knowledge and to be used as a reviewing tool. Moreover, the app enables students to recognize differences between sounds and their pronunciation. Consequently, our findings confirm that students prefer using m-learning apps rather than LMS for revision.

\section{FUTURE WORK}

The application will be a base for series of other researches in Arabic courses and it will be a support for using e-learning at universities.

\section{REFERENCES}

[1] A. Rabiee, Nazarian Z., \& Gharibshaeyan , R., "An Explanation for Internet Use Obstacles Concerning E-Learning in Iran". International Review of Research in Open and Distance Learning, 14(3), p361-376, 2013.

[2] C.Chang, Shen H.-Y., \& Liu , E. Z.-F. "University Faculty's Perspectives on the Roles of E-Instructors and Their Online Instruction Practice". International Review of Research in Open and Distance Learning, 15(3), p72-92, 2014.

[3] C.Gautreau, "Motivational Factors Affecting the Integration of a Learning Management System by Faculty. Journal of Educators Online, 8(1), p1-25, Jan, 2011.

[4] C.Keller \& Cernerud , L.,"Students' Perceptions of E-learning in University Education". Journal of Educational Media, 27( 1/2), p55-67, 2002.

[5] D.Coşkunçay \& özkan, s., "A model for instructors' adoption of learning management systems: empirical validation in higher education context". Turkish Online Journal of Educational Technology, 12(2), p13-25, 2013.

[6] D.Meehan \& Sabin , M., "QuizPower: a mobile app with app inventor and XAMPP service integration". SIGITE '13 Proceedings of the 14th annual ACM SIGITE conference on Information technology education (New York: ACM. pp. 103-108). 2013,doi:10.1145/2512276.2512300

[7] D.Wolber, Abelson, H., Spertus, E., \& Looney, L. “App Inventor 2", 2nd Edition. O'Reilly Media, October 2014.

[8] H.J. Jung, "Fostering an English Teaching Environment: Factors Influencing English as a Foreign Language Teachers' Adoption of Mobile Learning". Informatics in Education, 14(2), p219-241, 2015.

[9] H.Twakyondo \& Munaku, M., "Blackboard (Web resource); Moodle (Computer software); Chuo Kikuu cha Dar es Salaam; Learning Management System (Computer software); Courseware; Open source software. International Journal of Computing \& ICT Research, 6(2), p33-45, Dec,2012.

[10] I. Boticki, Baksa, J., peter seow, \& chee-kit looi, "Usage of a mobile social learning platform with virtual badges in a primary school". Computers \& Education, 86, p120-136, August, 2015.

[11] J.Sae-Khow, "Developing of Indicators of an E-Learning Benchmarking Model for Higher Education Institutions". Turkish Online Journal of Educational Technology - TOJET, 13(2),p35-43, 2014.
[12] K. Al-Busaidi A., "An empirical investigation linking learners' adoption of blended learning to their intention of full e-learning". Behaviour \& Information Technology, 32(11), p1168-1176, 2013. doi:10.1080/0144929X.2013.774047.

[13] K. F. Hashim, Tan, F. B., \& Rashid, A.,"Adult learners' intention to adopt mobile learning: A motivational perspective". British Journal of Educational Technology, 46(2), p381-390, 2015.

[14] K. M. titi \& Muhammad A., "Improvement Quality of LMS Through Application of Social Networking Sites". International Journal of Emerging Technologies in Learning, 8 (3), p48-51, 2013.

[15] K.Georgouli, Skalkidis, I., \& Guerreiro, P. A "Framework for Adopting LMS to Introduce e-Learning in a Traditional Course. Educational". Technology \& Society, 11(2), p227-240, . 2008.

[16] L.A. Guerrero, Ochoa, S., \& Collazos, C., "A mobile learning tool for improving grammar skills". Procedia - Social and Behavioral Sciences, 2(2), p1735-1739, 2010.

[17] L.Carter, Salyers, V., Carter, A., Myers, S., \& Barrett, P. The Search for Meaningful E-Learning at Canadian Universities: A MultiInstitutional Research Study. International Review of Research in Open and Distance Learning, 15(6), p313-347, 2014.

[18] M. A. Amasha; Salem Alkhalaf ,.”Using RSS 2.00 as a Model for uLearning to Develop e-Training in Saudi Arabia, International journal of information and communication technology education: an official publication of the Information Resources Management Association 6(7):6 - July 2016.

[19] M.A.Amasha, Salem Alkhalaf. "A Model of an E-Learning Web Site for Teaching and Evaluating Online", International Journal of Advanced Computer Science and Applications (IJACSA), 4(12), 2013. arXiv preprint arXiv: 1501.05578

[20] M.Demirbilek, Investigating Attitudes of Adult Educators towards Educational Mobile Media and Games in Eight European Countries. . Journal of Information Technology Education, 9, p235-247, 2010.

[21] M.Sarrab, AL-Shihi, H., \& AL-Manthari, B., "System Quality Characteristics For Selecting Mobile Learning Applications". Turkish Online Journal of Distance Education (TOJDE). , 16 (4), p18-27, Oct, 2015.

[22] P.Ling \& Ze, Z., "Developing Digital Learning Resources for the College Market in China". Publishing Research Quarterly, 4, p354-363, 2011.

[23] Q.Wu, "Designing a smartphone app to teach English (L2) vocabulary". Computers \& Education, 85, p170-179, July 2015.

[24] S. B. Asselin, "Learning and assistive technologies for college transition". Journal of Vocational Rehabilitation, 40(3), p 223-230, 2014.

[25] S. Papadakis, Kalogiannakis, M., Orfanakis, V., \& Zaranis, N., "Novice Programming Environments". Scratch \& App Inventor: a first comparison. IDEE '14 Proceedings of the 2014 Workshop on Interaction Design in Educational Environments (p. 1). New York ,NY, USA: ACM. doi: 10.1145/2643604.2643613

[26] S.Alkhalaf, Mohammed A. Amasha, Amal Al-Jarallah. "Using Mlearning as an Effective Device in Teaching and Learning in Higher Education in Saudi Arabia". International Journal of Information and Education Technology, 7(6). Jun,2017.

[27] S.D. "Using disruptive technologies to make digital connections: stories of media use and digital literacy in secondary classrooms". Educational Media International, 51(2), p109-123, 2014.

[28] S.Gabarre, C., Din, R., Shah, P. M., \& Karim, A. A. "Using Mobile Facebook As An LMS: Exploring Impeding Factors". GEMA Online Journal of Language Studies, 13(3), 99-115. 2013.

[29] S.Wichadee, "Factors Related to Faculty Members' Attitude and Adoption of a Learning Management System". Turkish Online Journal of Educational Technology, 14(4), p53-61,2015.

[30] S.Williams van Rooij, .Open-source learning management systems: a predictive model for higher education. Journal of Computer Assisted Learning, 28(2), p114-125, Apr 2012.

[31] X.Yang, Li, X., \& Lu, T. "Using mobile phones in college classroom settings: Effects of presentation mode and interest on concentration and achievement”. Computers \& Education, 88, p292-302, October 2015. 
[32] Y.C. Hsu \& Ching, Y.-H. "Mobile App Design for Teaching and Learning: Educators' Experiences in an Online Graduate Course". International Review of Research in Open and Distance Learning, 14(4), p117-139, 2013.

[33] Y.Lin, Chung , P., Yeh , R., \& Chen , Y., “An Empirical Study of College Students' Learning Satisfaction and Continuance Intention to Stick with a Blended e-Learning Environment" International Journal of Emerging Technologies in Learning, 11(2), p63-66, 2016.
[34] Z.Bogdanovic, Barac, D., Jovanic, B., Popovic, S., \& Radenkovic, B. "Evaluation of mobile assessment in a learning management system". British Journal of Educational Technology, 45(2), 231-244, 2013. doi:10.1111/bjet.12015

[35] Z.Wan, Compeau, D., \& Haggerty, N. "The Effects of Self-Regulated Learning Processes on E-Learning Outcomes in Organizational Settings". Journal of Management Information Systems, 29 (1), p307340, 2012. 